2015-03-04

\title{
Sequential Structural and Fluid Dynamics Analysis of Balloon- Expandable Coronary Stents: A Multivariable Statistical Analysis
}

\author{
David Martin \\ Technological University Dublin, david.martin@tudublin.ie \\ Fergal Boyle \\ Technological University Dublin, fergal.boyle@tudublin.ie
}

Follow this and additional works at: https://arrow.tudublin.ie/engschmecart

\section{Recommended Citation}

Martin, D., Boyle,F.: 'Sequential Structural and Fluid Dynamics Analysis of Balloon-Expandable Coronary Stents: A Multivariable Statistical Analysis', Cardiovascular Engineering and Technology (2015). doi:10.1007/s13239-015-0219-9

This Article is brought to you for free and open access by the School of Mechanical and Design Engineering at ARROW@TU Dublin. It has been accepted for inclusion in Articles by an authorized administrator of ARROW@TU Dublin. For more information, please contact arrow.admin@tudublin.ie, aisling.coyne@tudublin.ie, gerard.connolly@tudublin.ie.

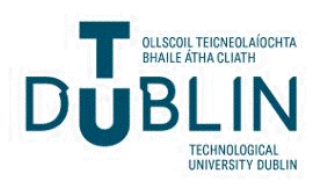




\title{
Sequential Structural and Fluid Dynamics Analysis of Balloon- Expandable Coronary Stents: A Multivariable Statistical Analysis
}

\author{
David Martin and Fergal Boyle \\ Department of Mechanical Engineering, Dublin Institute of Technology, Bolton Street, Dublin 1, Ireland
}

(Received 12 September 2014; accepted 21 February 2015)

Associate Editor James E. Moore oversaw the review of this article.

\begin{abstract}
Several clinical studies have identified a strong correlation between neointimal hyperplasia following coronary stent deployment and both stent-induced arterial injury and altered vessel hemodynamics. As such, the sequential structural and fluid dynamics analysis of balloon-expandable stent deployment should provide a comprehensive indication of stent performance. Despite this observation, very few numerical studies of balloon-expandable coronary stents have considered both the mechanical and hemodynamic impact of stent deployment. Furthermore, in the few studies that have considered both phenomena, only a small number of stents have been considered. In this study, a sequential structural and fluid dynamics analysis methodology was employed to compare both the mechanical and hemodynamic impact of six balloon-expandable coronary stents. To investigate the relationship between stent design and performance, several common stent design properties were then identified and the dependence between these properties and both the mechanical and hemodynamic variables of interest was evaluated using statistical measures of correlation. Following the completion of the numerical analyses, stent strut thickness was identified as the only common design property that demonstrated a strong dependence with either the mean equivalent stress predicted in the artery wall or the mean relative residence time predicted on the luminal surface of the artery. These results corroborate the findings of the large-scale ISAR-STEREO clinical studies and highlight the crucial role of strut thickness in coronary stent design. The sequential structural and fluid dynamics analysis methodology and the multivariable statistical treatment of the results described in this study should prove useful in the design of future balloon-expandable coronary stents.
\end{abstract}

Keywords-Stent, Coronary artery, Restenosis, Finite element analysis, Computational fluid dynamics, Equivalent stress, Relative residence time.

\section{INTRODUCTION}

Over the past two decades, several clinical studies have identified strong correlations between neointimal

Address correspondence to David Martin, Department of Mechanical Engineering, Dublin Institute of Technology, Bolton Street, Dublin 1, Ireland. Electronic mail: david.martin@dit.ie hyperplasia following coronary stent deployment and both stent-induced arterial injury $7,22,23,32,35,46,77,81,82,86$ and altered vessel hemodynamics. $6,17,18,20,21,52,71,79,88$ In light of these observations, a significant body of research has been carried out in this area. Due to the difficulty involved in the evaluation of these phenomena in an in vivo setting however, a large portion of this research has been carried out using computational methods of analysis. These computational methods of analysis employ sophisticated numerical techniques, such as the finite element and finite volume methods, to obtain approximate numerical solutions to complex physical problems. To date, a large number of studies have carried out computational structural (CS) analyses $1,4,5,14,15,19,25-29,37,44,53,54,57,59,62-64,72,73,78,80,85,87,90-92$ and computational fluid dynamics (CFD) analyses ${ }^{3,8,9,12,30,31,33,42,47-51,65,66,69,74-76,83,89}$ to exclusively evaluate either the mechanical or hemodynamic impact of coronary stent deployment. As neointimal hyperplasia has been strongly linked with both stent-induced arterial injury and altered vessel hemodynamics however, the sequential structural and fluid dynamics analysis of coronary stent deployment should provide a comprehensive indication of stent performance. Despite this observation, very few studies have adopted a sequential analysis methodology to assess both the mechanical and hemodynamic impact of stent deployment. ${ }^{2,11,38,43,58,60,61,70,93}$ Furthermore, no study has yet employed a sequential analysis methodology to compare and contrast the performance of several different coronary stent designs.

In studies carried out by Bolassino et al. in $2008,{ }^{2}$ Chiastra et al. in $2013^{11}$ and Martin et al. in $2014,{ }^{58}$ a sequential structural and fluid dynamics analysis methodology was employed to investigate the hemodynamic impact of several stent designs. Although a number of stent designs were evaluated in these studies, they focused exclusively on the hemodynamic impact of the stents and their mechanical impact was 


\section{Author's personal copy}

\section{Martin And F. Boyle}

not reported. In studies carried out by Zunino et al. in $2009,{ }^{93}$ Pant et al. in $2011^{70}$ and Keller et al. in $2014,{ }^{43}$ a sequential analysis methodology was employed to investigate the mechanical and hemodynamic impact of single stent designs. Although both the mechanical and hemodynamic impact of the stents were evaluated however, only a single stent design was considered in each study. In 2011, Morlacchi et al. ${ }^{61}$ applied a sequential analysis methodology to assess the mechanical and hemodynamic impact of a single stent design using different deployment strategies. Again, though both the mechanical and hemodynamic impact of the stent was evaluated, only a single stent design was considered. In 2012, Hsiao et al. ${ }^{38}$ employed a sequential analysis methodology to optimise the configuration of a single stent design. In this study, the mechanical impact of the stent within the artery was neglected and only a single stent design was considered. Finally, in 2014, Morlacchi et al. ${ }^{60}$ employed a sequential analysis methodology to investigate the mechanical and hemodynamic impact of both a conventional and a bifurcation stent design using different deployment strategies. To the authors' knowledge, this is the first study in which both the mechanical and hemodynamic impact of more than a single coronary stent design have been reported.

The aim of this study was to apply a sequential structural and fluid dynamics analysis methodology to compare and contrast both the mechanical and hemodynamic impact of six conventional balloon-expandable coronary stent designs. The applied methodology was divided into two stages. First, a geometric model of the stent was generated and a nonlinear CS analyses was carried out using ABAQUS (Dassault Systèmes, Simulia Corporation, Providence, RI, USA) to simulate its deployment in an idealised model of a coronary artery. The results of the CS analysis were then used to generate a realistically-deformed model of the stented coronary lumen and a transient CFD analysis was carried out using ANSYS CFX (ANSYS Inc., Canonsburg, PA, USA) to simulate pulsatile flow conditions in a human coronary artery. A multivariable statistical approach was then employed to compare and contrast both the mechanical and hemodynamic impact of the six investigated stents. The secondary aim of this study was to apply statistical measures of correlation to investigate the dependence between the common design properties of the investigated stents and both the mechanical and hemodynamic variables of interest.

\section{MATERIALS AND METHODS}

\section{Structural Analysis}

\section{Geometry and Discretisation}

The six investigated stents each resembled commercial coronary stents and were labelled from A to F as shown in Fig. 1. Of note, Stents $\mathrm{E}$ and $\mathrm{F}$ were identical and only differed in terms of their strut thickness. To carry out the CS analyses of each stent, a planar geometrical model of each repeating unit cell was first generated in ABAQUS. The repeating unit cell was then copied along both the axial and transverse directions to generate a planar model of the entire stent geometry. The planar stent model was then extruded by the corresponding strut thickness and discretised into a uniform finite element mesh. Each of the investigated stents were discretised using approximately $18,000-28,000$ reduced-integration continuum elements (C3D8R) based on the mesh convergence results presented in Appendix A. A cylindrical finite element model of the investigated
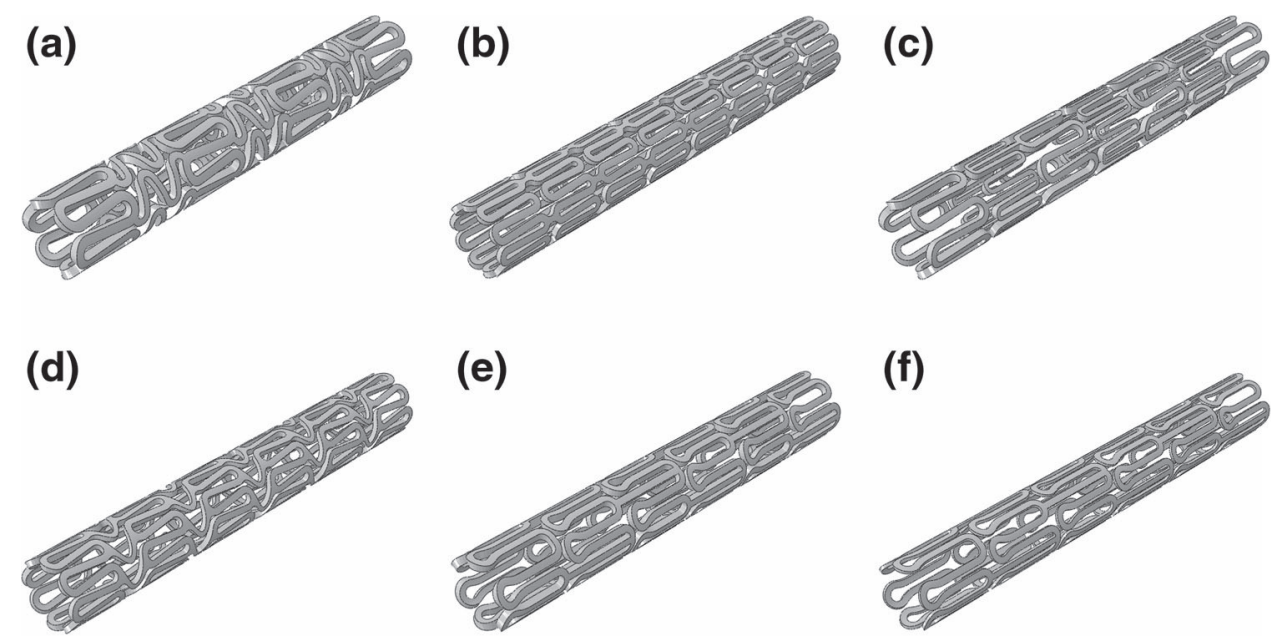

FIGURE 1. Geometrical configuration of (a) Stent A, (b) Stent B, (c) Stent C, (d) Stent D, (e) Stent E and (f) Stent F. 
stent was then generated by transforming the nodal coordinates from a Cartesian to a cylindrical coordinate system. This procedure effectively wrapped the planar stent mesh into a cylindrical configuration. The coincident nodes located at the mesh interface were then merged to generate a continuous finite element model of the investigated stent. Each of the stents was assigned a length of $8 \mathrm{~mm}$ and an internal diameter of $1 \mathrm{~mm}$. The remaining geometrical properties of the investigated stents were adopted from the literature and are presented in Table $1 .^{84}$

A realistic model of a balloon-tipped catheter was employed to simulate the deployment of the investigated stents. The balloon-tipped catheter, shown in Fig. 2, consisted of a guide wire, a catheter shaft and a tri-folded angioplasty balloon and has been described in detail in a previous study. ${ }^{57}$ The guide wire and catheter shaft were discretised using 740 and 13,104 reduced-integration continuum elements (C3D8R), respectively, while the angioplasty balloon was discretised using 12,462 reduced-integration membrane elements (M3D4R), based on the mesh convergence results presented in Appendix A. An idealised cylindrical model of a coronary artery was employed to investigate the mechanical impact of the investigated stents. As shown in Fig. 2, the artery was modelled as a straight cylindrical vessel and was assigned a fixed length of $20 \mathrm{~mm}$ and internal and external diameters of 2.7 and $4.5 \mathrm{~mm}$, respectively. The artery wall, which had a subsequent thickness of $0.9 \mathrm{~mm}$, was divided into three layers that represented the intima, media and adventitia and were assigned thicknesses of $0.24,0.32$ and $0.34 \mathrm{~mm}$, respectively. ${ }^{36}$ The artery was discretised into a uniform finite element mesh using 70,272 reduced-integration continuum elements (C3D8R) based on the mesh convergence results presented in Appendix A.

\section{Constitutive Behaviour}

The mechanical behaviour of the investigated stents was described using a rate-independent elastic-plastic material model with isotropic hardening. In this study, the investigated stents were assumed to be manufac- tured from 316L stainless steel and the data reported by Murphy et al. was employed to describe their elastic-plastic response. ${ }^{67}$ The elastic behaviour of the stents was described using an elastic modulus of $196 \mathrm{GPa}$ and a Poisson's ratio of 0.3 while their plastic behaviour was described using a multi-linear function characterised by an initial yield stress of $380 \mathrm{MPa}$ and an ultimate tensile strength of $750 \mathrm{MPa}$. The mechanical behaviour of the guide wire, the catheter shaft and the angioplasty balloon was described using isotropic linear elastic material models, and the data reported by Mortier et al. was adopted to describe their linear elastic response. ${ }^{64}$ The linear elastic response of the guide wire, catheter shaft and angioplasty balloon was described using an elastic modulus of $62 \mathrm{GPa}, 1 \mathrm{GPa}$ and $920 \mathrm{MPa}$ and a Poisson's ratio of $0.3,0.4$ and 0.4 , respectively. Finally, the mechanical behaviour of the intima, media and adventitia was described using third-order Ogden isotropic hyperelastic material model which is defined as follows:

$$
W=\sum_{i=1}^{n} \frac{2 \mu_{i}}{\alpha_{i}}\left(\bar{\lambda}_{1}^{\alpha_{i}}+\bar{\lambda}_{2}^{\alpha_{i}}+\bar{\lambda}_{3}^{\alpha_{i}}-3\right)+\sum_{i=1}^{n} \frac{1}{D_{i}}(J-1)^{2 i}
$$

(a)

(b)

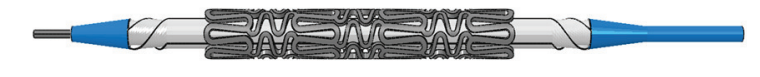

(c)

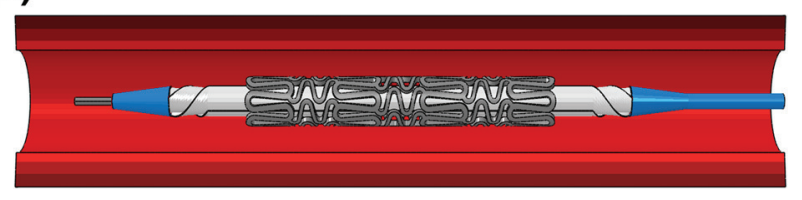

FIGURE 2. Geometrical configuration of (a) the balloon-tipped catheter, (b), a stent positioned over the balloon-tipped catheter and (c) a stent positioned over the balloon-tipped catheter inside the idealised cylindrical coronary artery.

TABLE 1. Geometrical properties of the investigated stents.

\begin{tabular}{llllll}
\hline Stent & \multicolumn{1}{c}{ A } & \multicolumn{1}{c}{ B } & C & D & F \\
\hline Cell configuration & Closed & Open & Open & Closed & Open \\
Link configuration & Peak-to-peak & Peak-to-peak & Peak-to-valley & Peak-to-peak & Peak-to-valley \\
Cell number (circumferential) & 6 & 5 & 3 & 8 & 3 \\
Cell number (longitudinal) & 3 & 7 & 6 & 5 & 3 \\
Strut thickness (mm) & 0.14 & 0.10 & 0.13 & 0.10 & 0.10 \\
Strut width (mm) & 0.13 & 0.10 & 0.09 & 0.13 & 0.10 \\
Stent-to-artery area $\left(\mathrm{mm}^{2}\right)$ & 12.35 & 15.02 & 9.47 & 12.46 & 0.10 \\
\hline
\end{tabular}




\section{Author's personal copy}

D. Martin And F. Boyle

The term $n$ denotes the order of the function, $\mu_{i}, \alpha_{i}$ and $D_{i}$ denote the temperature-dependent hyperelastic material constants, $\bar{\lambda}_{i}$ denote the deviatoric principal stretches and $J$ denotes the volume ratio. The data reported by Holzapfel et al. was employed to describe the nonlinear elastic response of the intima, media and adventitia $^{36}$ and the material constants that provided the best fit to the experimental data are presented in a Table 2.

\section{Boundary and Loading Conditions}

To simulate the deployment of the investigated stents, a uniform pressure load was applied to the inner surface of the angioplasty balloon. This pressure load was first increased until a stent-to-artery deployment ratio of $1.1: 1$, which is typical of clinical procedures, ${ }^{24}$ was achieved. The pressure load was then decreased to a value of $-0.01 \mathrm{MPa}$ to allow both the stent and the artery to recoil. To prevent rigid-body motions during the CS analyses, the nodes located at the extremities of the artery and the guide wire were fully-constrained while a small number of nodes located at the midsection of the stent were constrained in the axial and circumferential directions. Contact was then described using the general contact algorithm and friction was described using a Coulomb friction model. A static friction coefficient of 0.2 was adopted from Mortier et al. to describe the development of tangential frictional forces between all potential contact pairs and a mass-proportional Rayleigh damping coefficient of 8000 was adopted from DeBeule et al. to prevent nonphysical oscillations during the inflation of the angioplasty balloon. ${ }^{16,64}$

\section{Solution}

The CS analyses were carried out using the ABAQUS/Explicit solver and, as inertia is assumed to have a negligible role during stent deployment, a quasi-static approach was adopted. To obtain a computationally

TABLE 2. Hyperelastic material constants employed to describe the mechanical behaviour of the intimal, medial and adventitial layers of the coronary artery.

\begin{tabular}{llll}
\hline Constant & \multicolumn{1}{c}{ Intima } & \multicolumn{1}{c}{ Media } & \multicolumn{1}{c}{ Adventitia } \\
\hline$\mu_{1}$ & $-6.22 \mathrm{MPa}$ & $-1.67 \mathrm{MPa}$ & $-1.95 \mathrm{MPa}$ \\
$\mu_{2}$ & $3.84 \mathrm{MPa}$ & $1.04 \mathrm{MPa}$ & $1.18 \mathrm{MPa}$ \\
$\mu_{3}$ & $2.17 \mathrm{MPa}$ & $0.64 \mathrm{MPa}$ & $0.79 \mathrm{MPa}$ \\
$\alpha_{1}$ & 23.91 & 23.17 & 24.60 \\
$\alpha_{2}$ & 24.53 & 23.45 & 25.00 \\
$\alpha_{3}$ & 22.68 & 23.62 & 23.88 \\
$D_{1}$ & 0.78 & 4.35 & 3.88 \\
$D_{2}$ & 0 & 0 & 0 \\
$D_{3}$ & 0 & 0 & 0 \\
\hline
\end{tabular}

economic solution, the rate of loading was increased and a small degree of mass-scaling was introduced to artificially increase the size of the stable time increment. To ensure that the CS analyses remained quasistatic, a solution time of three seconds was specified and the total kinetic and internal energies were monitored for the duration of the analyses. The CS analyses were each completed within $24 \mathrm{~h}$ using four compute nodes of an SGI Altix ICE 8200EX cluster that is administered and maintained by the Irish Centre of High-End Computing. Each individual compute node consisted of two Xeon E5650 hex-core processors and 24 gigabytes of RAM.

\section{Fluid Dynamics Analysis}

\section{Geometry and Discretisation}

The deformed geometry of both the stent and the coronary artery were imported into ANSYS ICEM as triangulated surface meshes. As shown in Fig. 3, the luminal surface was then isolated and the deformed geometry of the stent was extracted. The distance both proximal and distal to the stent at which the lumen returned to its original diameter was measured and any elements located beyond these positions were removed.
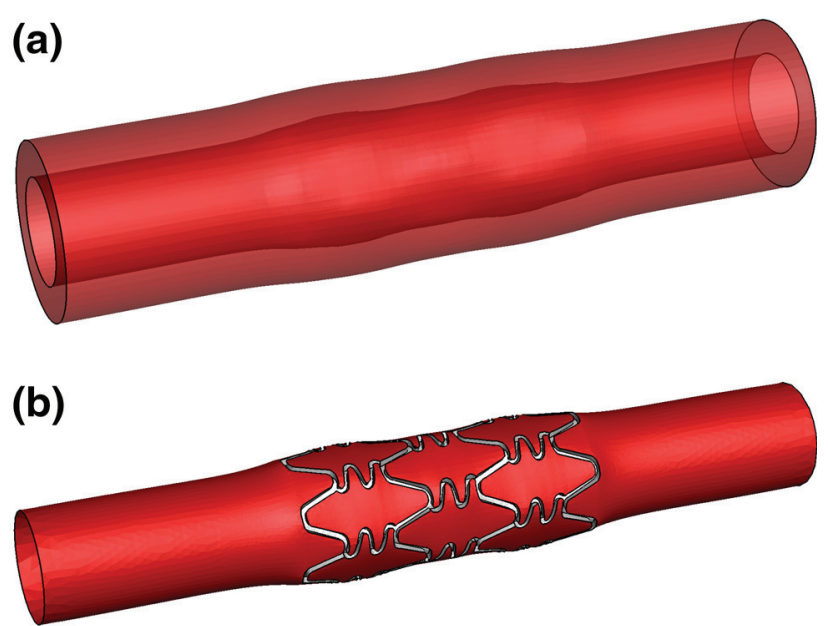

(c)

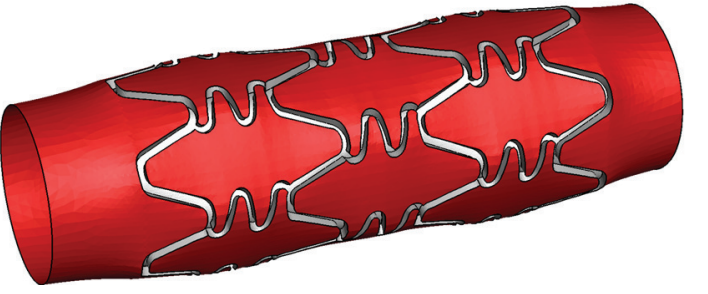

FIGURE 3. Generation of the CFD model of a stented coronary lumen: (a) deformed configuration of the artery, (b) isolation of the luminal surface and extraction of the deformed stent geometry and (c) removal of unnecessary length. 


\section{Author's personal copy}

Analysis of Balloon-Expandable Coronary Stents

The resulting meshes were then used to generate a realistically-deformed model of the stented coronary lumen. To ensure that the boundary conditions had no influence on the flow in the region of interest, an additional entrance and exit length of $32 \mathrm{~mm}$ was added to the extremities of each model. This additional length corresponded to the theoretical entrance length for fully-developed laminar flow in a $2.7 \mathrm{~mm}$ diameter straight cylinder subjected to an inlet velocity of $0.23 \mathrm{~m} / \mathrm{s}$. The models of the stented lumen were then discretised using 2-3 million tetrahedral elements based on the mesh convergence results presented in Appendix A. The resulting meshes were then imported into ANSYS CFX to configure the transient CFD analyses.

\section{Constitutive Behaviour}

Whole human blood is a non-Newtonian fluid and exhibits significant shear thinning behaviour at shear rates below $100 \mathrm{~s}^{-1} .^{39}$ As such, the density of the fluid was assigned a value of $1050 \mathrm{~kg} / \mathrm{m}^{3}$ and its dynamic viscosity was described using the Bird-Carreau model as follows:

$$
\mu=\mu_{\infty}+\left(\mu_{0}-\mu_{\infty}\right)\left[1+\left(\dot{\gamma} \lambda_{t}\right)^{2}\right]^{\left(\frac{q-1}{2}\right)}
$$

The term $\mu$ denotes the dynamic viscosity of the fluid, $\mu_{0}$ denotes the low shear viscosity, $\mu_{\infty}$ denotes the high shear viscosity, $\dot{\gamma}$ denotes the scalar shear strain rate, $\lambda_{t}$ denotes the time constant and $q$ denotes the power law index. The data reported by Jung et al. was employed to describe the variable viscosity of whole human blood. ${ }^{39}$ Specifically, the low and high shear viscosities were assigned values of 0.056 and $0.00345 \mathrm{~Pa} \cdot \mathrm{s}$, while the time constant and power law index were assigned values of 3.31 and $0.075 \mathrm{~s}$, respectively.

\section{Boundary and Loading Conditions}

During the CFD analyses, the domain was assumed to be rigid and a no-slip condition was specified on both the luminal surface and the exposed stent struts. A zero relative static pressure was specified at the domain outlet and a fully-developed Hagen-Poiseuille velocity profile was specified at the domain inlet. Although the velocity profile in a real coronary artery will be skewed by local curvature and tortuosity, the artery considered in this study is idealised as a straight cylindrical vessel and, as such, it is reasonable to assume a fully-developed velocity profile. To simulate pulsatile flow conditions, a transient velocity profile was adopted from Murphy et al. to describe the variation of the centreline velocity in a human left-anterior descending coronary artery during the cardiac cycle. ${ }^{65}$ As shown in Fig. 4, the velocity profile had

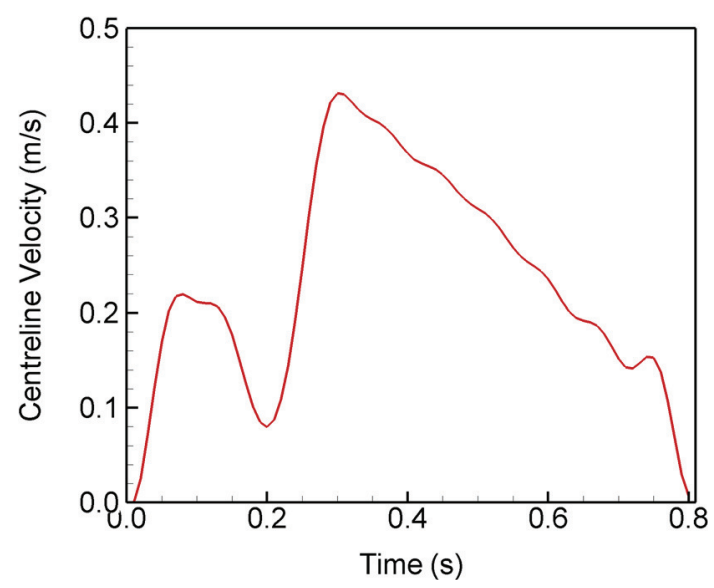

FIGURE 4. Transient velocity profile adopted to describe the variation of the centreline velocity in a human left-anterior descending coronary artery during a cardiac cycle.

mean and peak values of 0.23 and $0.43 \mathrm{~m} / \mathrm{s}$ which correspond to mean and peak Reynolds numbers of 189 and 353, respectively.

\section{Solution}

Following the specification of the boundary conditions, the conservation equations of mass and linear momentum were solved in ANSYS CFX using the coupled multigrid solver. As the peak Reynolds number for the velocity profile was below the conventional threshold at which transition to turbulence is expected, the flow in the domain was assumed to be laminar. Based on the results of the cycle and time step convergence studies presented in Appendix A, three consecutive cardiac cycles were simulated and thirty-two time steps were considered during each cycle. A convergence criterion of 0.0001 was then specified for the root mean square value of the velocity and density residuals based on the results of the tolerance convergence study presented in Appendix A. The CFD analyses were each completed within $24 \mathrm{~h}$ using a single core of a Hewlett-Packard xw8600 workstation that featured a Xeon X5450 quad-core processor and 32 gigabytes of RAM.

\section{Multivariable Statistical Analysis}

\section{Variables of Interest}

The performance of the investigated stent was first evaluated in terms of the rate of radial recoil (RR) and longitudinal foreshortening (LF). RR is defined as the difference between the stent diameter at maximum loading and unloading, and is calculated as follows:

$$
R R= \pm\left(\frac{D_{L O A D}-D_{U N L O A D}}{D_{L O A D}}\right) \times 100 \%
$$


As the diameter of a stent typically varies along both its length and circumference, an average diameter was determined from the average distance between the central axis and the nodes located at the inner apex of each crown. LF is defined as the difference in stent length prior to loading and unloading of the angioplasty balloon and is calculated as follows:

$$
L F= \pm\left(\frac{L_{U N L O A D}-L_{L O A D}}{L_{U N L O A D}}\right) \times 100 \%
$$

Following coronary stent deployment, sites of aggressive neointimal formation correspond with sites of excessive vascular injury, and this is attributed to increased rates of thrombus formation, inflammation, neointimal proliferation and extracellular synthesis. $7,22,23,32,35,46,77,81,82,86$ The mechanical impact of the investigated stents was evaluated in terms of the equivalent von Mises stress (ES) distribution predicted in the artery wall. The ES is calculated as follows:

$$
E S=\sqrt{\frac{3}{2} \sigma_{i j}^{\prime}: \sigma_{i j}^{\prime}}
$$

Here, the term $\sigma_{i j}^{\prime}$ denotes the deviatoric stress tensor. The ES distribution observed following the unloading of the angioplasty balloon was preferred to that observed at maximum loading when it is difficult to distinguish between stresses incurred due to balloon-artery and stent-artery interactions. Following coronary stent deployment, sites of aggressive neointimal hyperplasia also correspond to sites subjected to non-physiological flow conditions, and this has been attributed to increased endothelial dysfunction and permeability. ${ }^{6,17,18,20,21,52,71,79,88}$ The hemodynamic impact of the investigated stents was evaluated in terms of the relative residence time distribution predicted upon the lumen surface during the third cardiac cycle. The RRT accounts for temporal variations in both the magnitude and the orientation of the instantaneous wall shear stress vector and is calculated as follows:

$$
R R T=\frac{T}{\left|\int_{0}^{T} \tau_{i} d t\right|}
$$

The term $\tau_{i}$ denotes the instantaneous wall shear stress vector while $T$ denotes the cardiac period. High RRT values indicate regions of flow stagnation where endothelial dysfunction and high particle residence times are likely to be observed. ${ }^{34}$

\section{Statistical Analysis}

To fully elucidate the mechanical and hemodynamic impact of the stents, the weighted mean, standard deviation and skewness of the ES and RRT distributions were calculated. The weighted mean describes the central tendency of the respective distribution and was calculated as follows:

$$
\mu_{w}=\frac{\int_{w} \phi d w}{\int_{w} d w}=\frac{\sum_{i=1}^{N}\left(\phi_{i} d w_{i}\right)}{\sum_{i=1}^{N} d w_{i}}
$$

Here, $\phi_{i}$ denotes the value of the variable of interest at the $i$ th element/node, $d w_{i}$ denotes the volume/area at the $i$ th element/node and $N$ denotes the total number of elements/nodes in the domain. The weighted standard deviation and skewness were calculated as follows:

$$
\begin{gathered}
\sigma_{w}=\sqrt{\frac{\sum_{i=1}^{N}\left(\phi_{i}-\mu_{w}\right)^{2} d w_{i}}{\sum_{i=1}^{n} d w_{i}}} \\
s_{w}=\frac{\sum_{i=1}^{N}\left(\phi_{i}-\mu_{w}\right)^{3} d w_{i}}{\sum_{i=1}^{N} d w_{i} \sigma_{w}^{3}}
\end{gathered}
$$

The standard deviation and skewness describe the variance and asymmetry of the distribution about the corresponding mean, respectively. To investigate the relationship between stent design and performance, the number of longitudinal cells, number of circumferential cells, strut width, strut thickness and stent-to-artery surface area were identified as common geometrical design properties of the six investigated stents. The dependence between these common design properties and both the mean ES and RRT was then evaluated using the Spearman rank correlation coefficient. The Spearman coefficient (SC) is a statistical index that is employed to measure the strength of the assumed monotonic dependence between two independent variables $X$ and $Y$ and is calculated as follows:

$$
S C=\frac{\sum_{i=1}^{n}\left(x_{i}-\bar{x}\right)\left(y_{i}-\bar{y}\right)}{\sqrt{\sum_{i=1}^{n}\left(x_{i}-\bar{x}\right)^{2}} \sqrt{\sum_{i=1}^{n}\left(y_{i}-\bar{y}\right)^{2}}}
$$

The term $n$ denotes the sample size, $x_{i}$ and $y_{i}$ denote the ranked values of $X_{i}$ and $Y_{i}$ and $\bar{x}$ and $\bar{y}$ denote the mean values of $x_{i}$ and $y_{i}$, respectively. Where a high SC was calculated, the Pearson product moment correlation coefficient was then employed to calculate the strength of the linear dependence between the variables. The Pearson coefficient (PC) is a similar statistical index that is employed to measure the strength of the assumed linear dependence between two independent variables $X$ and $Y$ and is calculated as follows:

$$
P C=\frac{\sum_{i=1}^{n}\left(X_{i}-\bar{X}\right)\left(Y_{i}-\bar{Y}\right)}{\sqrt{\sum_{i=1}^{n}\left(X_{i}-\bar{X}\right)^{2}} \sqrt{\sum_{i=1}^{n}\left(Y_{i}-\bar{Y}\right)^{2}}}
$$

The term $n$ again denotes the sample size, $X_{i}$ and $Y_{i}$ denote the magnitudes of the variables $x$ and $y$ and $\bar{X}$ 


\section{Author's personal copy}

\section{Analysis of Balloon-Expandable Coronary Stents}

and $\bar{Y}$ denote the mean values of the variables $X_{i}$ and $Y_{i}$, respectively.

\section{RESULTS}

\section{Deployment Characteristics}

As shown in Fig. 5, the deployment of the investigated stents was characterised by a rapid initial expansion that commenced at the stent extremities. This phenomenon is referred to as dog-boning and is well documented in the literature. ${ }^{45}$ As shown in Table 3, the highest rate of RR of $-4.74 \%$ was observed with Stent F. This was attributed to the fact that Stent F had a highly non-uniform distribution of cells and the lowest strut thickness of $0.05 \mathrm{~mm}$. Conversely, the lowest rate of RR of $-3.28 \%$ was observed with Stent B. This was attributed to the fact that Stent B had a much more uniform distribution of cells and a relatively high strut thickness of $0.10 \mathrm{~mm}$. As shown in Table 3, the highest rate of LF of $-7.67 \%$ was also observed with Stent B. This was attributed to the fact that Stent B did not have any flexible link elements which tend to inhibit LF during stent deployment. Conversely, the lowest rate of LF of $+3.13 \%$ was observed with Stent E. Although uncommon, stent elongation has been reported in previous experimental and numerical studies in the literature. ${ }^{45,91}$ The slight elongation of Stents $\mathrm{E}$ and $\mathrm{F}$ was attributed to the fact that their strut segments were interconnected by long, inflexible articulations that inhibit LF during deployment. Overall, the predicted rates of RR and LF were in good general agreement with experimental values reported in the literature. $]^{13}$

\section{Equivalent Stress}

The ES distribution predicted in the artery wall for each of the investigated stents is shown in Fig. 6. In each of the CS analyses, the peak values of ES were observed in the intimal layer of the artery wall. As shown in Table 4, the highest mean ES of $10.72 \mathrm{kPa}$ was observed with Stent A. This was attributed to the fact that Stent A had the highest strut thickness of $0.14 \mathrm{~mm}$ and also exhibited a relatively low rate of RR. High stresses were also observed with Stent A as its flexible link elements expanded to a greater diameter than its strut elements and this imposed a circumferential stretch on the tissue in its repeating cells. Conversely, the lowest mean ES of $3.49 \mathrm{kPa}$ was observed with Stent F. This was attributed to the fact that Stent $F$ had the lowest strut thickness of $0.05 \mathrm{~mm}$ and also exhibited the highest rate of RR. For each of the investigated stents, the standard deviation of the ES distribution was relatively high. This implies a high variance about the mean ES and was attributed to the fact that the majority of the artery was subjected to either relatively high or low values of ES. For each of the investigated stents, the

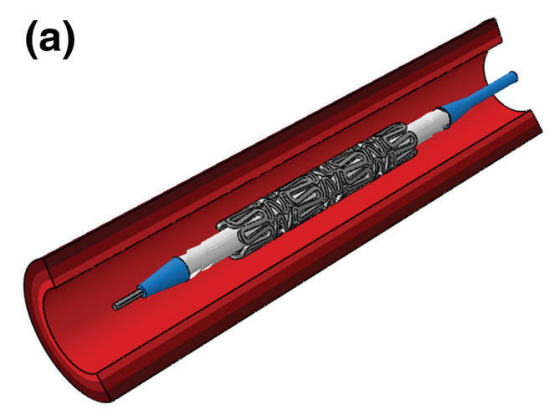

(b)
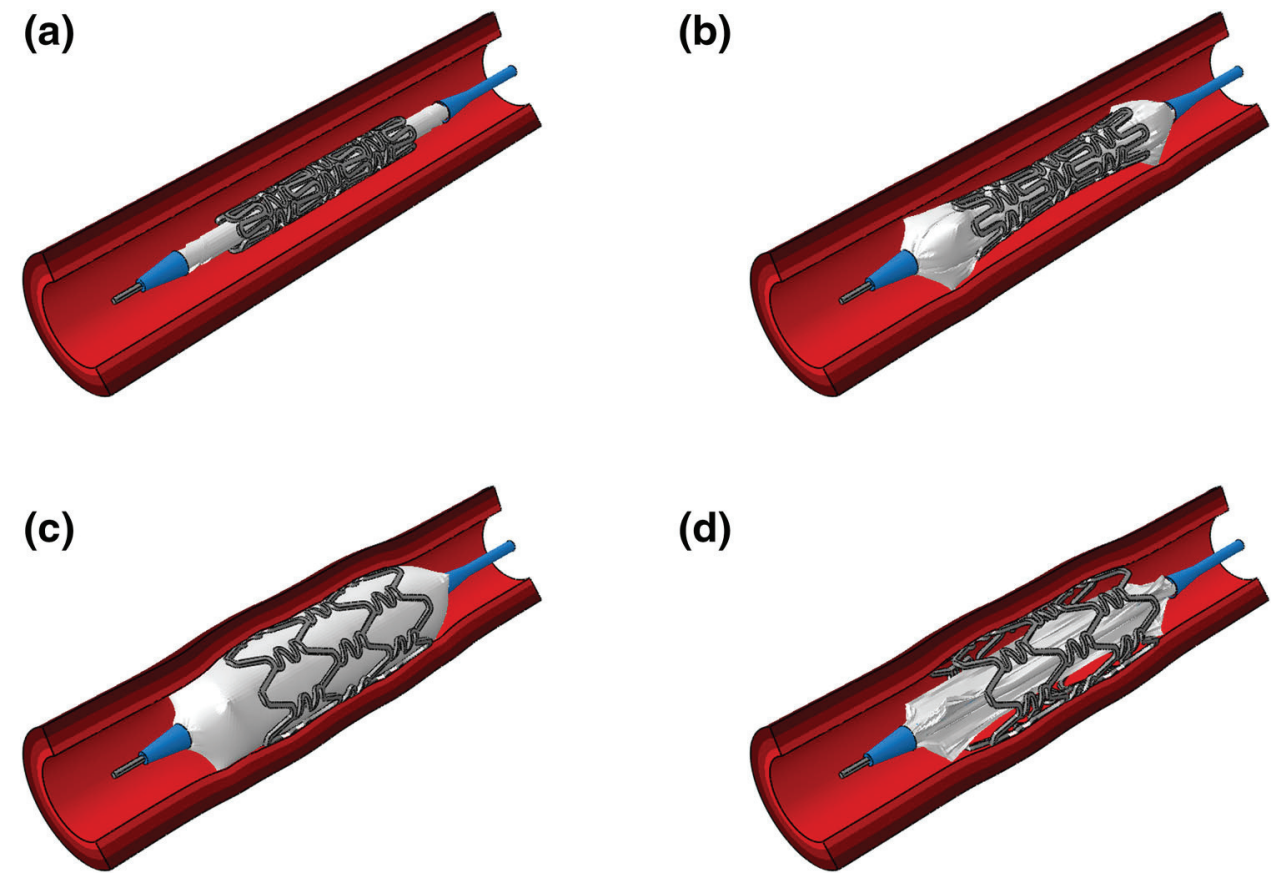

FIGURE 5. Configuration of Stent A (a) prior to loading, (b) during loading, (c) at maximum loading and (d) at unloading of the angioplasty balloon. 


\section{Author's personal copy}

\section{Martin And F. Boyle}

skewness of the ES distribution was between 1.8 and 2.3. This implies that the ES distributions were skewed slightly to the right such that the majority of the artery was subjected to ES values that were marginally lower than the mean ES. Based on these results, it is likely that Stent $\mathrm{A}$ and $\mathrm{F}$ would have the greatest and the least impact on the mechanical environment in the coronary artery, respectively.

\section{Relative Residence Time}

The RRT distribution predicted on the luminal surface for each of the investigated stents is shown in Fig. 7. In each of the CFD analyses, the peak values of RRT were predicted next to the stent struts where

TABLE 3. Deployment characteristics of the investigated stents.

\begin{tabular}{lcccc} 
Stent & Final diameter $(\mathrm{mm})$ & Final length $(\mathrm{mm})$ & $\mathrm{RR}(\%)$ & LF $(\%)$ \\
\hline A & 2.93 & 7.63 & -3.37 & -4.66 \\
B & 2.95 & 7.39 & -3.28 & -7.67 \\
C & 2.92 & 7.70 & -4.15 & -3.79 \\
D & 2.91 & 7.71 & -3.48 & -3.61 \\
E & 2.92 & 8.25 & -3.69 & +3.13 \\
F & 2.88 & 8.22 & -4.74 & +2.75 \\
\hline
\end{tabular}

localised regions of flow separation, recirculation and reattachment were observed. Regions of high RRT were also apparent where the strut and link elements were located in close proximity to one another or aligned perpendicular to the main flow direction. As shown in Table 4, the highest mean RRT of $4.97 \mathrm{~Pa}^{-1}$ was observed with Stent A. This implies that Stent A subjected the greatest portion of the luminal surface to coincident regions of low and oscillatory wall shear stress. This was attributed to the fact that Stent A had the highest strut thickness of $0.14 \mathrm{~mm}$ and a large number of its link elements were both in close proximity to one another and aligned perpendicular to the main flow direction. Conversely, the lowest mean RRT of $1.36 \mathrm{~Pa}^{-1}$ was observed with Stent F. This was attributed to the fact that Stent $F$ had the lowest strut thickness of $0.05 \mathrm{~mm}$ and the vast majority of its link elements were located far apart from one another and aligned parallel to the main flow direction. For each of the investigated stents, the standard deviation of the RRT distribution was relatively high. This implies a high variance about the mean RRT and was attributed to the fact that the majority of the luminal surface was subjected to either relatively high or low values of RRT. For each of the investigated stents, the skewness of the RRT distribution was extremely high and ran-
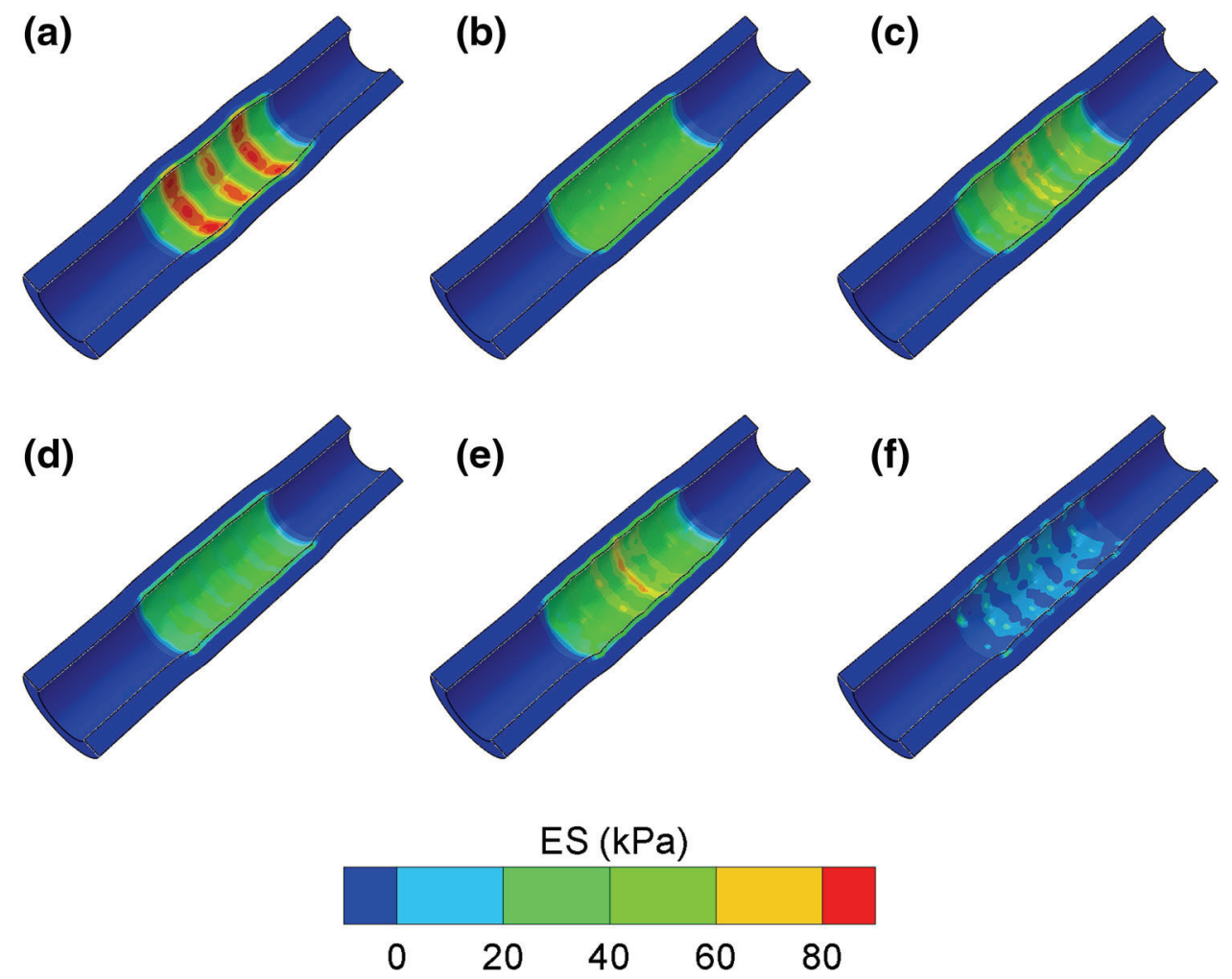

FIGURE 6. ES distribution predicted in the artery wall following the deployment of (a) Stent A, (b) Stent B, (c) Stent C, (d) Stent D, (e) Stent $E$ and (f) Stent F. 


\section{Author's personal copy}

\section{Analysis of Balloon-Expandable Coronary Stents}

ged from a value of 9-151. This implies that the RRT distributions were skewed strongly to the right such that the vast majority of the luminal surface was subjected to RRT values that were significantly lower than the mean RRT. Based on these results, it is likely that Stents $A$ and $F$ would have the greatest and the least impact on the hemodynamic environment in the coronary artery, respectively.

\section{Stent Design and Performance}

When the six investigated stents were ranked from best to worst in terms of the mean ES and RRT, Stents $\mathrm{D}$ and $\mathrm{F}$ were consistently ranked as the best

TABLE 4. Statistical analysis of the predicted ES and RRT distributions for each of the investigated stents.

\begin{tabular}{lrrrrrrr}
\hline & \multicolumn{3}{c}{ ES } & & \multicolumn{3}{c}{ RRT } \\
\cline { 2 - 3 } \cline { 6 - 7 } Stent & $\mu_{w}(\mathrm{kPa})$ & $\sigma_{w}(\mathrm{kPa})$ & $s_{w}(-)$ & $\mu_{w}\left(\mathrm{~Pa}^{-1}\right)$ & $\sigma_{w}\left(\mathrm{~Pa}^{-1}\right)$ & $s_{w}(-)$ \\
\hline A & 10.72 & 16.94 & 2.25 & & 4.97 & 11.80 & 10.07 \\
B & 8.83 & 12.52 & 1.85 & & 4.19 & 12.24 & 15.62 \\
C & 8.79 & 12.97 & 2.04 & & 4.82 & 27.38 & 150.95 \\
D & 7.34 & 10.18 & 1.80 & & 3.89 & 9.96 & 9.10 \\
E & 9.21 & 13.01 & 1.90 & & 4.26 & 14.05 & 29.28 \\
F & 3.49 & 4.61 & 2.08 & & 1.36 & 4.12 & 38.86 \\
\hline
\end{tabular}

performing stents while Stent A was consistently ranked as the worst-performing stent. Comparing the properties of the investigated stents however, it is difficult to determine why Stents D and F were consistently ranked as the best-performing stents. Stent D had a closed-cell, peak-to-peak configuration and a high number of circumferential cells while Stent F had an open-cell, peak-to-valley configuration and a low number of circumferential cells. It is also difficult to determine why Stents A, C and E were consistently ranked poorly. Stent A had a closed-cell, peak-to-peak configuration and a high number of circumferential cells while Stents C and E had an open-cell, peak-tovalley configuration and a low number of circumferential cells.

As shown in Table 5, the only common design property of the six investigated stents that demonstrated a strong monotonic dependence with either the mean ES or RRT was strut thickness. Specifically, a strong positive monotonic dependence $(0.70<\mathrm{SC}<$ 0.90) was observed between strut thickness and the mean $\mathrm{ES}(\mathrm{SC}=0.853)$ while a very strong positive monotonic dependence $(0.90<\mathrm{SC}<1.00)$ was observed between strut thickness and the mean RRT $(\mathrm{SC}=0.971)$. In order to investigate the functional nature of these dependencies, a scatter plot was gen-
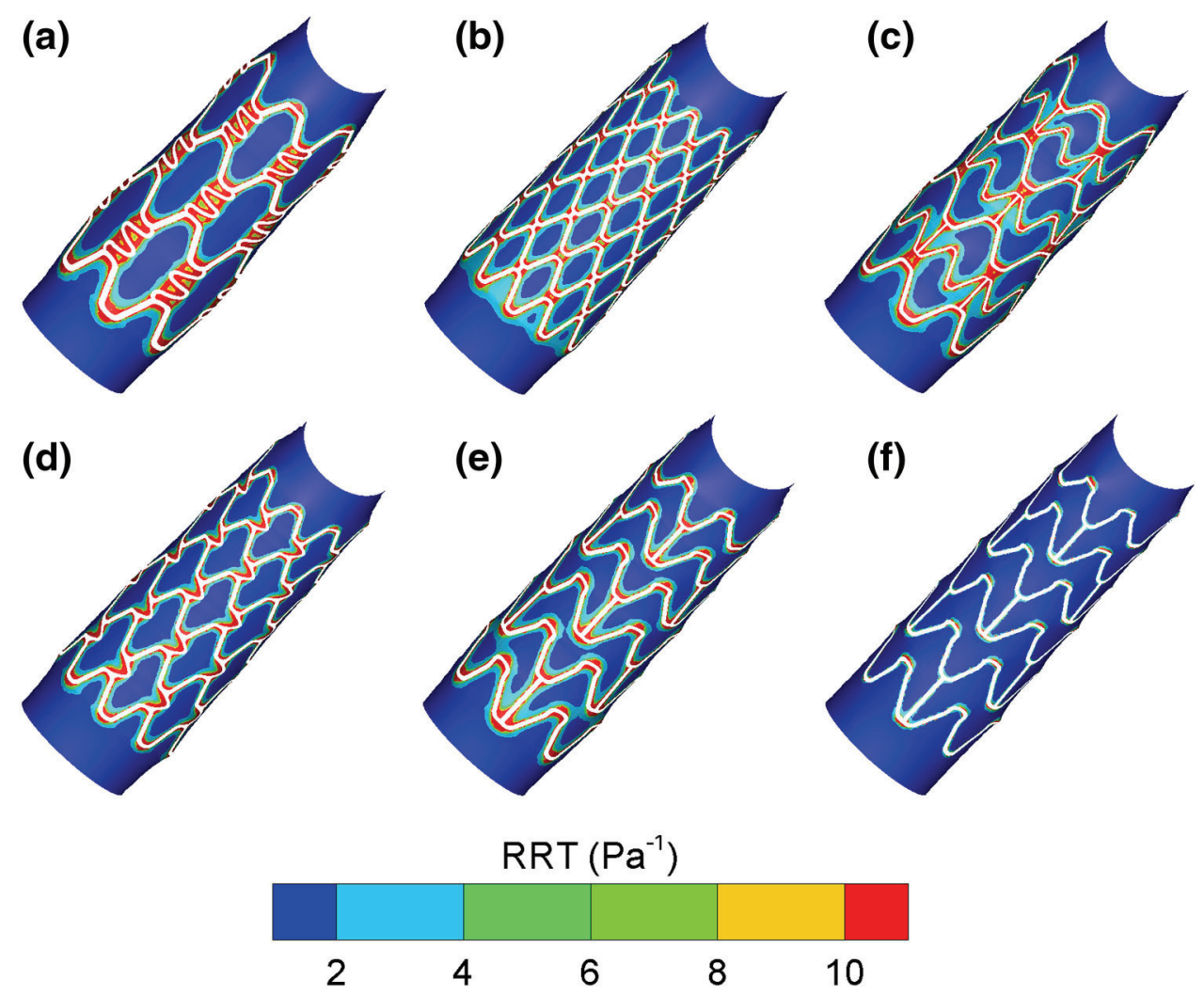

FIGURE 7. RRT distribution predicted on the luminal surface for (a) Stent A, (b) Stent B, (c) Stent C, (d) Stent D, (e) Stent E and (f) Stent F. 
TABLE 5. Calculated Spearman coefficient for each combination of the common geometric design properties and both the mean ES and RRT

\begin{tabular}{lrr}
\hline Design variable & ES & RRT \\
\hline Longitudinal cells & -0.273 & -0.213 \\
Circumferential cells & 0.152 & 0.030 \\
Strut thickness & 0.853 & 0.971 \\
Strut width & 0.507 & 0.169 \\
Stent-to-artery surface area & 0.145 & -0.232 \\
\hline
\end{tabular}

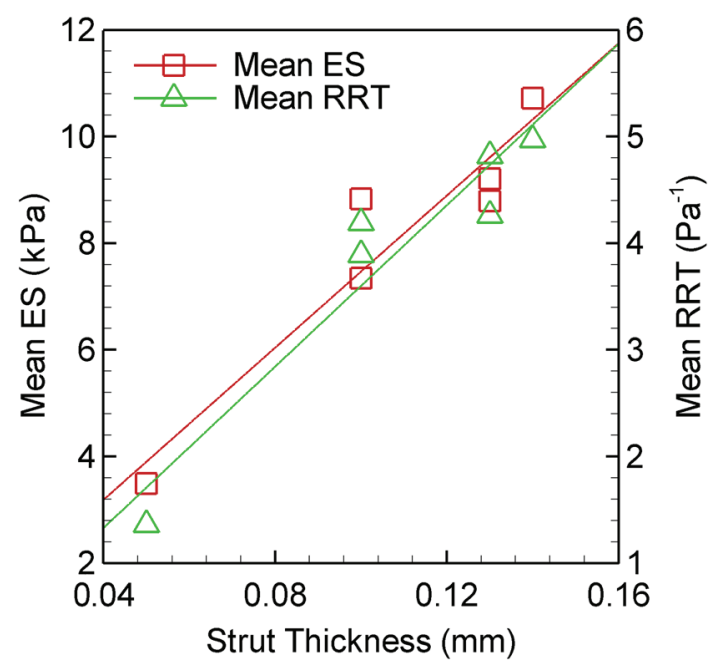

FIGURE 8. Approximate linear dependence observed between strut thickness and both the mean ES (red data points) and RRT (green data points).

erated for each pair of correlated variables. As shown in Fig. 8, the functional nature of the monotonic dependence was approximately linear. The strength of this assumed linear dependence was therefore evaluated using the PC. Following the calculation of the $\mathrm{PC}$, a very strong positive linear dependence $(0.90<\mathrm{PC}<1.00)$ was observed between strut thickness and both the mean ES $(\mathrm{PC}=0.950)$ and the mean RRT (0.971). These results suggest that strut thickness is likely to have a significant influence on both the mechanical and hemodynamic impact of coronary stent deployment. As such, stainless steel stents that feature a relatively low strut thickness are likely to be less susceptible to neointimal hyperplasia, and subsequent in-stent restenosis, in a clinical setting.

\section{DISCUSSION}

In a randomised clinical study carried out by Kastrati et al. in 2001, 1147 patients were randomly assigned to receive one of five stainless steel coronary stents. ${ }^{41}$ At one year follow-up, the primary end-point of event-free survival ranged from 69.4 to $82.4 \%$ for the five different stents $(\mathrm{p}<0.05)$. Based on these results, it was concluded that stent design has a major impact on the clinical outcome following coronary stent deployment. The results presented in this study corroborate these findings in that that the severity of the mechanical and hemodynamic impact predicted within the coronary artery varied for each of the six investigated stents. The numerical results further demonstrate the important relationship between stent design and performance. Despite the success of drugeluting stents since their introduction in 2003, the primary aim of stent design should include the minimisation of neointimal hyperplasia through the reduction of both the mechanical and hemodynamic impact within the coronary artery. This is especially true in population subsets where high risk factors, such as diabetes and complex lesions, are encountered.

The results of this study also corroborate the findings of the ISAR-STEREO trials. The ISAR-STEREO-I and ISAR-STEREO-II trials were large-scale clinical studies carried out by Kastrati et al. in 2001 and Pache et al. in 2003, respectively, in which over 600 patients were randomly assigned to receive either a thin $(0.05 \mathrm{~mm})$ or thick $(0.13-0.14 \mathrm{~mm})$ strut stent for the treatment of symptomatic coronary heart disease. ${ }^{40,68}$ At 6 month follow-up in both trials, the incidence of angiographic in-stent restenosis was significantly higher $(p<0.05)$ for patients treated with the thick strut stents. Based on these results, it was concluded that strut thickness has a major impact on the clinical outcome following coronary stent deployment. The results presented in this study also corroborate this finding in that a strong correlation was identified between increased strut thickness and an increased mechanical and hemodynamic impact within the coronary artery. Furthermore, the design of Stents A, E and F is comparable to that of the commercial stents investigated in the ISAR-STEREO trials. Specifically, Stent A resembles the BX-Velocity stent (Johnson \& Johnson, New Brunswick, NJ, USA) while Stents E and F resemble the thin and thick strut variations of the Multilink Duet stent (Abbott Laboratories, Abbott Park, IL, USA), respectively. As shown in Table 6, the predicted performance of the investigated stents was in good agreement with the clinical performance of the commercial stents in so far as the stents that produced the higher mean ES and RRT in this study also produced the higher rates of angiographic in-stent restenosis at shortterm follow-up in both of the clinical trials.

The results of this study should be interpreted in terms of several potential limitations. Firstly, though current-generation coronary stents are primarily manufactured from high-strength metallic alloys, such as cobalt-chromium, ${ }^{56}$ the six investigated stents in 
TABLE 6. Comparison of the predicted performance of Stents $A, E$ and $F$ with the clinical performance of three comparable commercial stents, as reported in the three comparable commercial stents, as reported in the
ISAR-STEREO-I (top) and ISAR-STEREO-II (bottom) clinical studies.

\begin{tabular}{lccc}
\hline & $\begin{array}{c}\text { Numerical } \\
\text { mean } \\
\text { ES }(\mathrm{kPa})\end{array}$ & $\begin{array}{c}\text { Numerical } \\
\text { mean } \\
\mathrm{RRT}\left(\mathrm{Pa}^{-1}\right)\end{array}$ & $\begin{array}{c}\text { Clinical } \\
\text { in-stent } \\
\text { restenosis (\%) }\end{array}$ \\
\hline ISAR-STEREO-I Trial & & & \\
E & 9.21 & 4.26 & 25.8 \\
F & 3.49 & 1.36 & 15.0 \\
ISAR-STEREO-II Trial & & & \\
A & 10.72 & 4.97 & 31.4 \\
F & 3.49 & 1.36 & 17.9 \\
\hline
\end{tabular}

this study were each assigned the properties of stainless steel. As such, the results and conclusions of this study cannot be extrapolated to current-generation devices. Though limiting, this approach is not uncommon in the literature and many recent numerical studies have investigated stainless steel coronary stent designs. ${ }^{14,19,20,25,28-31,43,57,58,64-66,69,70,73,80,89,91,92}$ Furthermore, one of the primary aims of this study was to assess the predictive nature of the numerical approach. This required that the relative performance of at least two of the investigated stents had been evaluated in large-scale clinical trials. Though many clinical trials have been carried out to assess the relative performance of stents manufactured from high-strength metallic alloys, the majority of these trials have also included drug and/or polymer coatings, which are not accounted for in the current numerical model. In light of this issue, Stents A, E and F were specifically investigated so that their predicted performance could be compared to that of the commercial stents investigated in the ISAR-STEREO trials. To date, the ISARSTEREO trials remain two of the largest clinical studies in which the relative performance of two uncoated stents has been investigated in a large-scale, head-to-head manner. Stents B, C and D were then included to increase the sample size to six stents, as required for the statistical analyses.

The results of the analyses are also limited by the assumed geometrical/material models and the applied boundary conditions. Specifically, balloon-expandable stents are typically cut from metallic tubes, crimped to a low profile and loaded onto a delivery system. During this process, the stent is first subjected to plastic deformations and then allowed to recoil. This initial crimping process results in the development of residual stresses within the stent struts that can have a subsequent effect upon the deformation of the stent during the deployment procedure. To simplify the analyses however, the crimping procedure was neglected in this study and the investigated stents were initially modelled in a stress-free configuration. Though limiting, the deployment of Stent A was found to be in excellent quantitative and qualitative agreement with that of a comparable commercial stent. ${ }^{55}$ Secondly, both the tortuosity of the coronary artery and the presence of an atherosclerotic plaque are neglected. Since these features vary significantly from one person to another and are dependent on the artery of interest, it is difficult to identify a single idealised geometry that adequately accounts for each feature. Although patient-specific models provide an excellent description of tortuous, atherosclerotic coronary arteries, the results and conclusions derived from these models are only applicable to a single patient and it is debatable whether they should be generalised to the entire population. An alternative approach to this issue was recently proposed by Conway et al. who employed idealised models of coronary arteries to investigate the mechanical impact of stent deployment in a series of vessels that featured various degrees of tortuosity, plaque severity and plaque properties. ${ }^{14}$ Though a population-specific approach would improve the present study of stent performance, the computational effort required to investigate both the mechanical and hemodynamic impact of six stents in a series of idealised arteries featuring various degrees of arterial tortuosity, plaque severity and plaque properties was deemed beyond the scope of the current work. This approach is therefore suggested as a potential avenue for future research in this area.

The material model adopted to describe the mechanical behaviour of the coronary artery during the CS analysis is another limitation of the proposed methodology. In reality, human arterial tissue exhibits a strong anisotropic mechanical response which is likely to have a major impact on the stresses incurred in the artery wall. In this study however, the mechanical behaviour of the artery was instead described using isotropic hyperelastic material models based on experimental data derived from circumferentially-orientated samples of human arterial tissue. Though limiting, this approach is plausible, as the dominant arterial response during coronary stent deployment is in the circumferential direction. With regard to the CFD analysis, one of the major limitations associated with the proposed methodology arises from the assumption of a rigid domain. This assumption is also plausible however, as the deployment of a stent is likely to considerably stiffen the lumen in the region of interest. Furthermore, a recent study reported by Chiastra et al. demonstrated negligible differences in the wall shear stress distribution when both rigid and compliant domains were considered. ${ }^{10}$ Finally, the specification of a zero relative static pressure at the domain outlet results in the development of nonphysiological pressure gradients during the CFD ana- 


\section{Author's personal copy}

D. Martin And F. Boyle

lysis. This assumption is also plausible, as the domain is assumed to be rigid and the velocity field is not influenced by the absolute values of pressure.

\section{CONCLUSION}

In this study, a sequential structural and fluid dynamics analysis methodology has been employed to investigate both the mechanical and hemodynamic impact of several balloon-expandable coronary stent designs for the first time. The dependence between the common design properties of the investigated stents and both the mechanical and hemodynamic variables of interest was also evaluated using statistical measures of correlation for the first time. From both a mechanical and hemodynamic perspective, Stents D and $F$ were ranked as the best performing stents while Stents A, C and E were ranked as the worst-performing stents. Strut thickness was also identified as the only common stent design property that demonstrated a strong monotonic or linear dependence with either the mean ES predicted in the artery wall or the mean RRT predicted on the luminal surface. These results corroborate the findings of the previous clinical studies and highlight the crucial role of strut thickness in the design of stainless steel stents. Furthermore, the predicted performance of three of the investigated stents was found to be in good agreement with the clinical performance of three comparable commercial stents, as reported in the large-scale ISAR-STEREO trials. Given the good agreement between the predicted results and the clinical results, the numerical approach presented in this study may be applied with some confidence to the pre-clinical design and optimisation of future balloon-expandable coronary stents.

\section{ELECTRONIC SUPPLEMENTARY MATERIAL}

The online version of this article (doi: 10.1007/s13239-015-0219-9) contains supplementary material, which is available to authorized users.

\section{ACKNOWLEDGMENTS}

This research was funded by Dublin Institute of Technology under the Fiosraigh scholarship programme. The authors would also like to acknowledge the SFI/HEA Irish Centre of High-End Computing for the provision of computational facilities and support.

\section{CONFLICT OF INTEREST}

David Martin and Fergal Boyle declare that they have no conflict of interest.

\section{STATEMENT OF HUMAN STUDIES}

No human studies were carried out by the authors for this article.

\section{STATEMENT OF ANIMAL STUDIES}

No animal studies were carried out by the authors for this article.

\section{REFERENCES}

${ }^{1}$ Auricchio, F., M. Di Loreto, and E. Sacco. Finite-element analysis of a stenotic artery revascularization through a stent insertion. Comput. Methods Biomech. Biomed. Eng. 4:249-263, 2001. doi:10.1080/10255840108908007.

${ }^{2}$ Balossino, R., F. Gervaso, F. Migliavacca, and G. Dubini. Effects of different stent designs on local hemodynamics in stented arteries. J. Biomech. 41:1053-1061, 2008. doi: 10.1016/j.jbiomech.2007.12.005.

${ }^{3}$ Banerjee, R., S. Devarakonda, and D. Rajamohan. Developed pulsatile flow in a deployed coronary stent. Biorheology 44:91-102, 2007.

${ }^{4}$ Bedoya, J., C. A. Meyer, L. H. Timmins, M. R. Moreno, and J. E. Moore. Effects of stent design parameters on normal artery wall mechanics. J. Biomech. Eng. 128:757-765, 2006. doi:10.1115/1.2246236.

${ }^{5}$ Capelli, C., F. Gervaso, L. Petrini, G. Dubini, and F. Migliavacca. Assessment of tissue prolapse after balloon-expandable stenting: influence of stent cell geometry. Med. Eng. Phys. 31:441-447, 2009. doi:10.1016/j.medengphy.2008.11.002.

${ }^{6}$ Carlier, S. G., L. C. A. van Damme, C. P. Blommerde, J. J. Wentzel, G. van Langehove, S. Verheye, et al. Augmentation of wall shear stress inhibits neointimal hyperplasia after stent implantation: inhibition through reduction of inflammation? Circulation 107:2741-2746, 2003. doi:10.1161/01.CIR.0000066914.95878.6D.

${ }^{7}$ Carter, A. J., J. R. Laird, A. Farb, W. Kufs, D. C. Wortham, and R. Virmani. Morphologic characteristics of lesion formation and time course of smooth muscle cell proliferation in a porcine proliferative restenosis model. $J$. Am. Coll. Cardiol. 24:1398-1405, 1994.

${ }^{8}$ Chen, H. Y., J. Hermiller, A. K. Sinha, M. Sturek, L. Zhu, and G. S. Kassab. Effects of stent sizing on endothelial and vessel wall stress: potential mechanisms for in-stent restenosis. J. Appl. Physiol. 106:1686-1691, 2009. doi: 10.1152/japplphysiol.91519.2008.

${ }^{9}$ Chen, H. Y., I. D. Moussa, C. Davidson, and G. S. Kassab. Impact of main branch stenting on endothelial shear stress: role of side branch diameter, angle and lesion. J. R. Soc. Interface 9:1187-1193, 2012. doi:10.1098/rsif.2011.0675.

${ }^{10}$ Chiastra, C., F. Migliavacca, M. Á. Martínez, and M. Malvè. On the necessity of modelling fluid-structure interaction for stented coronary arteries. J. Mech. Behav. Biomed. Mater. 34:217-230, 2014. doi:10.1016/ j.jmbbm.2014.02.009.

${ }^{11}$ Chiastra, C., S. Morlacchi, D. Gallo, U. Morbiducci, R. Cárdenes, I. Larrabide, et al. Computational fluid dynamic simulations of image-based stented coronary bifurcation 
models. J. R. Soc. Interface 10:20130193, 2013. doi: 10.1098/rsif.2013.0193.

${ }^{12}$ Chiastra, C., S. Morlacchi, S. Pereira, G. Dubini, and F. Migliavacca. Computational fluid dynamics of stented coronary bifurcations studied with a hybrid discretization method. Eur. J. Mech. B 35:76-84, 2012. doi: 10.1016/j.euromechflu.2012.01.011.

${ }^{13}$ Colombo, A., G. Stankovic, and J. W. Moses. Selection of coronary stents. J. Am. Coll. Cardiol. 40:1021-1033, 2002. doi:10.1016/S0735-1097(02)02123-X.

${ }^{14}$ Conway, C., F. Sharif, J. P. McGarry, and P. E. McHugh. A computational test-bed to assess coronary stent implantation mechanics using a population-specific approach. Cardiovasc. Eng. Technol. 3:374-387, 2012. doi: 10.1007/s13239-012-0104-8.

${ }^{15}$ David Chua, S. N., B. W. MacDonald, and M. S. J. Hashmi. Finite element simulation of slotted tube (stent) with the presence of plaque and artery by balloon expansion. J. Mater. Process. Technol. 155-156:1772-1779, 2004. doi:10.1016/j.jmatprotec.2004.04.396.

${ }^{16}$ De Beule, M., P. Mortier, S. G. Carlier, B. Verhegghe, R. Van Impe, and P. Verdonck. Realistic finite element-based stent design: the impact of balloon folding. J. Biomech. 41:383-389, 2008. doi:10.1016/j.jbiomech.2007.08.014.

${ }^{17}$ Dehlaghi, V., S. Najarian, and M. T. Shadpour. Effect of stent geometry on phase shift between pressure and flow waveforms in stented human coronary artery. Am. J. Appl. Sci. 5:340-346, 2008. doi:10.3844/ajassp.2008.340.346.

${ }^{18}$ Duraiswamy, N., R. T. Schoephoerster, and J. E. Moore. Comparison of near-wall hemodynamic parameters in stented artery models. J. Biomech. Eng. 131:061006, 2009. doi:10.1115/1.3118764.

${ }^{19}$ Early, M., and D. J. Kelly. The role of vessel geometry and material properties on the mechanics of stenting in the coronary and peripheral arteries. Proc. Inst. Mech. Eng. H 224:465-476, 2010.

${ }^{20}$ Ellwein, L. M., H. Otake, T. J. Gundert, B.-K. Koo, T. Shinke, Y. Honda, et al. Optical coherence tomography for patient-specific 3D artery reconstruction and evaluation of wall shear stress in a left circumflex coronary artery. Cardiovasc Eng Technol 2:212-227, 2011. doi: 10.1007/s13239-011-0047-5.

${ }^{21}$ Faik, I., R. Mongrain, R. L. Leask, J. Rodes-Cabau, E. Larose, and $\mathrm{O}$. Bertrand. Time-dependent 3D simulations of the hemodynamics in a stented coronary artery. Biomed. Mater. 2:S28-S37, 2007. doi:10.1088/1748-6041/2/1/S05.

${ }^{22}$ Farb, A., G. Sangiorgi, A. J. Carter, V. M. Walley, W. D. Edwards, R. S. Schwartz, et al. Pathology of acute and chronic coronary stenting in humans. Circulation 99:44-52, 1999.

${ }^{23}$ Farb, A., D. K. Weber, F. D. Kolodgie, A. P. Burke, and R. Virmani. Morphological predictors of restenosis after coronary stenting in humans. Circulation 105:2974-2980, 2002.

${ }^{24}$ Fujise, K., P. Yhip, H. Anderson, G. Schroth, O. Rosales, and R. Smalling. Balloon to artery ratio, not inflation pressure, correlates with adequate stent deployment: size is more important than pressure. J. Interv. Cardiol. 13:223-229, 2000. doi:10.1111/j.1540-8183.2000.tb00296.x.

${ }^{25}$ Gastaldi, D., S. Morlacchi, R. Nichetti, C. Capelli, G. Dubini, L. Petrini, et al. Modelling of the provisional sidebranch stenting approach for the treatment of atherosclerotic coronary bifurcations: effects of stent positioning. Biomech. Model. Mechanobiol. 9:551-561, 2010. doi: 10.1007/s10237-010-0196-8.
${ }^{26}$ Gervaso, F., C. Capelli, L. Petrini, S. Lattanzio, L. Di Virgilio, and F. Migliavacca. On the effects of different strategies in modelling balloon-expandable stenting by means of finite element method. J. Biomech. 41:1206-1212, 2008. doi:10.1016/j.jbiomech.2008.01.027.

${ }^{27}$ Gijsen, F. J. H., F. Migliavacca, S. Schievano, L. Socci, L. Petrini, A. Thury, et al. Simulation of stent deployment in a realistic human coronary artery. Biomed. Eng. 7:23, 2008. doi:10.1186/1475-925X-7-23.

${ }^{28} \mathrm{Gu}$, L., S. Zhao, and S. Froemming. Arterial wall mechanics and clinical implications after coronary stenting: comparisons of three stent designs. Int. J. Appl. Mech. 04:1250013, 2012. doi:10.1142/S1758825112500135.

${ }^{29} \mathrm{Gu}$, L., S. Zhao, A. K. Muttyam, and J. M. Hammel. The relation between the arterial stress and restenosis rate after coronary stenting. J. Med. Dev. 4:031005, 2010. doi: $10.1115 / 1.4002238$.

${ }^{30}$ Gundert, T. J., R. J. Dholakia, D. McMahon, and J. F. LaDisa. Computational fluid dynamics evaluation of equivalency in hemodynamic alterations between implanted into an idealized coronary artery. J. Med. Device 7:011004, 2013. doi:10.1115/1.4023413.

${ }^{31}$ Gundert, T. J., A. L. Marsden, W. Yang, and J. F. LaDisa. Optimization of cardiovascular stent design using computational fluid dynamics. J. Biomech. Eng. 134:011002, 2012. doi: $10.1115 / 1.4005542$.

${ }^{32}$ Gunn, J., N. Arnold, K. H. Chan, L. Shepherd, D. C. Cumberland, and D. C. Crossman. Coronary artery stretch versus deep injury in the development of in-stent neointima. Heart 88:401-405, 2002.

${ }^{33}$ He, Y., N. Duraiswamy, A. O. Frank, and J. E. Moore. Blood flow in stented arteries: a parametric comparison of strut design patterns in three dimensions. J. Biomech. Eng. 127:637-647, 2005.

${ }^{34}$ Himburg, H. A., D. M. Grzybowski, A. L. Hazel, J. A. LaMack, X.-M. Li, and M. H. Friedman. Spatial comparison between wall shear stress measures and porcine arterial endothelial permeability. Am. J. Physiol. Heart Circ. Physiol. 286:H1916-H1922, 2004. doi: 10.1152/ajpheart.00897.2003.

${ }^{35}$ Hoffmann, R., G. S. Mintz, R. Mehran, K. M. Kent, A. D. Pichard, L. F. Satler, et al. Tissue proliferation within and surrounding Palmaz-Schatz stents is dependent on the aggressiveness of stent implantation technique. Am. J. Cardiol. 83:1170-1174, 1999.

${ }^{36}$ Holzapfel, G. A., G. Sommer, C. T. Gasser, and P. Regitnig. Determination of layer-specific mechanical properties of human coronary arteries with nonatherosclerotic intimal thickening and related constitutive modeling. Am. J. Physiol. Heart Circ. Physiol. 289:H2048-H2058, 2005. doi:10.1152/ajpheart.00934.2004.

${ }^{37}$ Holzapfel, G. A., M. Stadler, and T. C. Gasser. Changes in the mechanical environment of stenotic arteries during interaction with stents: computational assessment of parametric stent designs. J. Biomech. Eng. 127:166-180, 2005.

${ }^{38}$ Hsiao, H.-M., Y.-H. Chiu, K.-H. Lee, and C.-H. Lin. Computational modeling of effects of intravascular stent design on key mechanical and hemodynamic behavior. Comput. Des. 44:757-765, 2012. doi:10.1016/j.cad. 2012.03.009.

${ }^{39}$ Jung, H., J. Choi, and C. Park. Asymmetric flows of nonNewtonian fluis in symmetric stenosed artery. Korea Aust. Rheol. J. 16:101-108, 2004.

${ }^{40}$ Kastrati, A., J. Mehilli, J. Dirschinger, F. Dotzer, H. Schühlen, F. J. Neumann, et al. Intracoronary stenting and 


\section{Martin and F. Boyle}

angiographic results: strut thickness effect on restenosis outcome (ISAR-STEREO) trial. Circulation 103:28162821, 2001.

${ }^{41}$ Kastrati, A., J. Mehilli, J. Dirschinger, J. Pache, K. Ulm, H. Schühlen, et al. Restenosis after coronary placement of various stent types. Am. J. Cardiol. 87:34-39, 2001.

${ }^{42}$ Katritsis, D. G., A. Theodorakakos, I. Pantos, M. Gavaises, N. Karcanias, and E. P. Efstathopoulos. Flow patterns at stented coronary bifurcations: computational fluid dynamics analysis. Circ. Cardiovasc. Interv. 5:530-539, 2012. doi:10.1161/CIRCINTERVENTIONS. 112.968347.

${ }^{43}$ Keller, B. K., C. M. Amatruda, D. R. Hose, J. Gunn, P. V. Lawford, G. Dubini, et al. Contribution of mechanical and fluid stresses to the magnitude of in-stent restenosis at the Level of individual stent struts. Cardiovasc. Eng. Technol. 5:164-175, 2014. doi:10.1007/s13239-014-0181-y.

${ }^{44}$ Kiousis, D. E., T. C. Gasser, and G. A. Holzapfel. A numerical model to study the interaction of vascular stents with human atherosclerotic lesions. Ann. Biomed. Eng. 35:1857-1869, 2007. doi:10.1007/s10439-007-9357-z.

${ }^{45}$ Kiousis, D. E., A. R. Wulff, and G. A. Holzapfel. Experimental studies and numerical analysis of the inflation and interaction of vascular balloon catheter-stent systems. Ann. Biomed. Eng. 37:315-330, 2009. doi:10.1007/s10439008-9606-9.

${ }^{46}$ Kornowski, R., M. K. Hong, F. O. Tio, O. Bramwell, $\mathrm{H}$. $\mathrm{Wu}$, and $\mathrm{M}$. B. Leon. In-stent restenosis: contributions of inflammatory responses and arterial injury to neointimal hyperplasia. J. Am. Coll. Cardiol. 31:224-230, 1998.

${ }^{47}$ LaDisa, J. F., I. Guler, L. E. Olson, D. A. Hettrick, J. R. Kersten, D. C. Warltier, et al. Three-dimensional computational fluid dynamics modeling of alterations in coronary wall shear stress produced by stent implantation. Ann. Biomed. Eng. 31:972-980, 2003.

${ }^{48}$ LaDisa, J. F., L. E. Olson, H. A. Douglas, D. C. Warltier, J. R. Kersten, and P. S. Pagel. Alterations in regional vascular geometry produced by theoretical stent implantation influence distributions of wall shear stress: analysis of a curved coronary artery using 3D computational fluid dynamics modeling. Biomed. Eng. 5:40, 2006. doi: 10.1186/1475-925X-5-40.

${ }^{49}$ LaDisa, J. F., L. E. Olson, I. Guler, D. A. Hettrick, S. H. Audi, J. R. Kersten, et al. Stent design properties and deployment ratio influence indexes of wall shear stress: a three-dimensional computational fluid dynamics investigation within a normal artery. J. Appl. Physiol. 97:424-430, 2004. doi:10.1152/japplphysiol.01329.2003.

${ }^{50}$ LaDisa, J. F., L. E. Olson, I. Guler, D. A. Hettrick, J. R. Kersten, D. C. Warltier, et al. Circumferential vascular deformation after stent implantation alters wall shear stress evaluated with time-dependent 3D computational fluid dynamics models. J. Appl. Physiol. 98:947-957, 2005. doi: 10.1152/japplphysiol.00872.2004.

${ }^{51}$ LaDisa, J. F., L. E. Olson, D. A. Hettrick, D. C. Warltier, J. R. Kersten, and P. S. Pagel. Axial stent strut angle influences wall shear stress after stent implantation: analysis using 3D computational fluid dynamics models of stent foreshortening. Biomed. Eng. 4:59, 2005. doi:10.1186/1475925X-4-59.

${ }^{52}$ LaDisa, J. F., L. E. Olson, R. C. Molthen, D. A. Hettrick, P. F. Pratt, M. D. Hardel, et al. Alterations in wall shear stress predict sites of neointimal hyperplasia after stent implantation in rabbit iliac arteries. Am. J. Physiol. Heart
Circ. Physiol. 288:H2465-H2475, 2005. doi:10.1152/ ajpheart.01107.2004.

${ }^{53}$ Lally, C., F. Dolan, and P. J. Prendergast. Cardiovascular stent design and vessel stresses: a finite element analysis. $J$. Biomech. 38:1574-1581, 2005. doi:10.1016/j.jbiomech. 2004.07.022.

${ }^{54}$ Liang, D. K., D. Z. Yang, M. Qi, and W. Q. Wang. Finite element analysis of the implantation of a balloon-expandable stent in a stenosed artery. Int. J. Cardiol. 104:314-318, 2005. doi:10.1016/j.ijcard.2004.12.033.

${ }^{55}$ Martin, D. Sequential structural and fluid dynamics analysis of balloon-expandable coronary stents. Dublin: Dublin Institute of Technology, 2013.

${ }^{56}$ Martin, D. M., and F. J. Boyle. Drug-eluting stents for coronary artery disease: a review. Med. Eng. Phys. 33:148-163, 2011. doi:10.1016/j.medengphy.2010.10.009.

${ }^{57}$ Martin, D., and F. Boyle. Finite element analysis of balloon-expandable coronary stent deployment: influence of angioplasty balloon configuration. Int. J. Numer. Method Biomed. Eng. 29:1161-1175, 2013. doi:10.1002/cnm.2557.

${ }^{58}$ Martin, D. M., E. A. Murphy, and F. J. Boyle. Computational fluid dynamics analysis of balloon-expandable coronary stents: influence of stent and vessel deformation. Med. Eng. Phys. 36:1047-1056, 2014. doi:10.1016/j. medengphy.2014.05.011.

${ }^{59}$ Migliavacca, F., L. Petrini, P. Massarotti, S. Schievano, F. Auricchio, and G. Dubini. Stainless and shape memory alloy coronary stents: a computational study on the interaction with the vascular wall. Biomech. Model. Mechanobiol. 2:205-217, 2004. doi:10.1007/s10237-0040039-6.

${ }^{60}$ Morlacchi, S., C. Chiastra, E. Cutrì, P. Zunino, F. Burzotta, L. Formaggia, et al. Stent deformation, physical stress, and drug elution obtained with provisional stenting, conventional culotte and Tryton-based culotte to treat bifurcations: a virtual simulation study. EuroIntervention 9:1441-1453, 2014. doi:10.4244/EIJV9I12A242.

${ }^{61}$ Morlacchi, S., C. Chiastra, D. Gastaldi, G. Pennati, G. Dubini, and F. Migliavacca. Sequential structural and fluid dynamic numerical simulations of a stented bifurcated coronary artery. J. Biomech. Eng. 133:121010, 2011. doi: $10.1115 / 1.4005476$.

${ }^{62}$ Morlacchi, S., S. G. Colleoni, R. Cárdenes, C. Chiastra, J. L. Diez, I. Larrabide, et al. Patient-specific simulations of stenting procedures in coronary bifurcations: two clinical cases. Med. Eng. Phys. 35:1272-1281, 2013. doi: 10.1016/j.medengphy.2013.01.007.

${ }^{63}$ Mortier, P., M. De Beule, D. Van Loo, B. Verhegghe, and P. Verdonck. Finite element analysis of side branch access during bifurcation stenting. Med. Eng. Phys. 31:434-440, 2009. doi:10.1016/j.medengphy.2008.11.013.

${ }^{64}$ Mortier, P., G. A. Holzapfel, M. De Beule, D. Van Loo, Y. Taeymans, P. Segers, et al. A novel simulation strategy for stent insertion and deployment in curved coronary bifurcations: comparison of three drug-eluting stents. Ann. Biomed. Eng. 38:88-99, 2010. doi:10.1007/s10439009-9836-5.

${ }^{65}$ Murphy, J. B., and F. J. Boyle. A numerical methodology to fully elucidate the altered wall shear stress in a stented coronary artery. Cardiovasc. Eng. Technol. 1:256-268, 2010. doi:10.1007/s13239-010-0028-0.

${ }^{66}$ Murphy, J. B., and F. J. Boyle. A full-range, multi-variable, CFD-based methodology to identify abnormal near-wall hemodynamics in a stented coronary artery. Biorheology 47:117-132, 2010. doi:10.3233/BIR-2010-0568. 


\section{Author's personal copy}

\section{Analysis of Balloon-Expandable Coronary Stents}

${ }^{67}$ Murphy, B. P., P. Savage, P. E. McHugh, and D. F. Quinn. The stress-strain behavior of coronary stent struts is size dependent. Ann. Biomed. Eng. 31:686-691, 2003.

${ }^{68}$ Pache, J., A. Kastrati, J. Mehilli, H. Schühlen, F. Dotzer, J. Hausleiter, et al. Intracoronary stenting and angiographic results: strut thickness effect on restenosis outcome (ISARSTEREO-2) trial. J. Am. Coll. Cardiol. 41:1283-1288, 2003. doi:10.1016/S0735-1097(03)00119-0.

${ }^{69}$ Pant, S., N. W. Bressloff, A. I. J. Forrester, and N. Curzen. The influence of strut-connectors in stented vessels: a comparison of pulsatile flow through five coronary stents. Ann. Biomed. Eng. 38:1893-1907, 2010. doi: 10.1007/s10439-010-9962-0.

${ }^{70}$ Pant, S., G. Limbert, N. P. Curzen, and N. W. Bressloff. Multiobjective design optimisation of coronary stents. Biomaterials 32:7755-7773, 2011. doi:10.1016 j.biomaterials.2011.07.059.

${ }^{71}$ Papafaklis, M. I., C. V. Bourantas, P. E. Theodorakis, C. S. Katsouras, K. K. Naka, D. I. Fotiadis, et al. The effect of shear stress on neointimal response following sirolimusand paclitaxel-eluting stent implantation compared with bare-metal stents in humans. JACC Cardiovasc. Interv. 3:1181-1189, 2010. doi:10.1016/j.jcin.2010.08.018.

${ }^{72}$ Pericevic, I., C. Lally, D. Toner, and D. J. Kelly. The influence of plaque composition on underlying arterial wall stress during stent expansion: the case for lesion-specific stents. Med. Eng. Phys. 31:428-433, 2009. doi: 10.1016/j.medengphy.2008.11.005.

${ }^{73}$ Ragkousis, G. E., N. Curzen, and N. W. Bressloff. Simulation of longitudinal stent deformation in a patientspecific coronary artery. Med. Eng. Phys. 36:467-476, 2014. doi:10.1016/j.medengphy.2014.02.004.

${ }^{74}$ Rajamohan, D., R. K. Banerjee, L. H. Back, A. A. Ibrahim, and M. A. Jog. Developing pulsatile flow in a deployed coronary stent. J. Biomech. Eng. 128:347-359, 2006. doi:10.1115/1.2194067.

${ }^{75}$ Rikhtegar, F., F. Pacheco, C. Wyss, K. S. Stok, H. Ge, R. J. Choo, et al. Compound ex vivo and in silico method for hemodynamic analysis of stented arteries. PLoS One 8:e58147, 2013. doi:10.1371/journal.pone.0058147.

${ }^{76}$ Rikhtegar, F., C. Wyss, K. S. Stok, D. Poulikakos, R. Müller, and V. Kurtcuoglu. Hemodynamics in coronary arteries with overlapping stents. J. Biomech. 47:505-511, 2014. doi:10.1016/j.jbiomech.2013.10.048.

${ }^{77}$ Rogers, C., and E. R. Edelman. Endovascular stent design dictates experimental restenosis and thrombosis. Circulation 91:2995-3001, 1995.

${ }^{78}$ Rogers, C., D. Y. Tseng, J. C. Squire, and E. R. Edelman. Balloon-artery interactions during stent placement: a finite element analysis approach to pressure, compliance, and stent design as contributors to vascular injury. Circ. Res. 84:378-383, 1999

${ }^{79}$ Sanmartín, M., J. Goicolea, C. García, J. García, A. Crespo, J. Rodríguez, et al. Influence of shear stress on in-stent restenosis: in vivo study using $3 \mathrm{D}$ reconstruction and computational fluid dynamics. Rev. Esp. Cardiol. 59:20-27, 2006.

${ }^{80}$ Schiavone, A., L. G. Zhao, and A. A. Abdel-Wahab. Effects of material, coating, design and plaque composition on stent deployment inside a stenotic artery-finite element simulation. Mater. Sci. Eng. C 42:479-488, 2014. doi: 10.1016/j.msec.2014.05.057.

${ }^{81}$ Schulz, C., R. A. Herrmann, C. Beilharz, J. Pasquantonio, and E. Alt. Coronary stent symmetry and vascular injury determine experimental restenosis. Heart 83:462-467, 2000.

${ }^{82}$ Schwartz, R. S., K. C. Huber, J. G. Murphy, W. D. Edwards, A. R. Camrud, R. E. Vlietstra, et al. Restenosis and the proportional neointimal response to coronary artery injury: results in a porcine model. J. Am. Coll. Cardiol. 19:267-274, 1992.

${ }^{83}$ Seo, T., L. G. Schachter, and A. I. Barakat. Computational study of fluid mechanical disturbance induced by endovascular stents. Ann. Biomed. Eng. 33:444-456, 2005.

${ }^{84}$ Serruys, P., and B. Rensing. Handbook of coronary stents. Kentucky: Taylor \& Francis, 2001.

${ }^{85}$ Takashima, K., T. Kitou, K. Mori, and K. Ikeuchi. Simulation and experimental observation of contact conditions between stents and artery models. Med. Eng. Phys. 29:326-335, 2007. doi:10.1016/j.medengphy.2006.04.003.

${ }^{86}$ Timmins, L. H., M. W. Miller, F. J. Clubb, and J. E. Moore. Increased artery wall stress post-stenting leads to greater intimal thickening. Lab. Invest. 91:955-967, 2011. doi:10.1038/labinvest.2011.57.

${ }^{87}$ Timmins, L. H., M. R. Moreno, C. A. Meyer, J. C. Criscione, A. Rachev, and J. E. Moore. Stented artery biomechanics and device design optimization. Med. Biol. Eng. Comput. 45:505-513, 2007. doi:10.1007/s11517007-0180-3.

${ }^{88}$ Wentzel, J. J., R. Krams, J. C. Schuurbiers, J. A. Oomen, J. Kloet, W. J. van Der Giessen, et al. Relationship between neointimal thickness and shear stress after Wallstent implantation in human coronary arteries. Circulation 103:1740-1745, 2001

${ }^{89}$ Williams, A. R., B.-K. Koo, T. J. Gundert, P. J. Fitzgerald, and J. F. LaDisa. Local hemodynamic changes caused by main branch stent implantation and subsequent virtual side branch balloon angioplasty in a representative coronary bifurcation. J. Appl. Physiol. 109:532-540, 2010. doi: 10.1152/japplphysiol.00086.2010.

${ }^{90} \mathrm{Wu}$, W., W.-Q. Wang, D.-Z. Yang, and M. Qi. Stent expansion in curved vessel and their interactions: a finite element analysis. J. Biomech. 40:2580-2585, 2007. doi: 10.1016/j.jbiomech.2006.11.009.

${ }^{91}$ Zahedmanesh, H., D. John Kelly, and C. Lally. Simulation of a balloon expandable stent in a realistic coronary arteryDetermination of the optimum modelling strategy. J. Biomech. 43:2126-2132, 2010. doi:10.1016/j.jbiomech. 2010.03.050.

${ }^{92}$ Zahedmanesh, H., and C. Lally. Determination of the influence of stent strut thickness using the finite element method: implications for vascular injury and in-stent restenosis. Med. Biol. Eng. Comput. 47:385-393, 2009. doi: 10.1007/s11517-009-0432-5.

${ }^{93}$ Zunino, P., C. D’Angelo, L. Petrini, C. Vergara, C. Capelli, and F. Migliavacca. Numerical simulation of drug eluting coronary stents: mechanics, fluid dynamics and drug release. Comput. Methods Appl. Mech. Eng. 198:3633-3644, 2009. doi:10.1016/j.cma.2008.07.019. 